\title{
Characteristics and outcomes of Behçet's syndrome patients with Coronavirus Disease 2019: a case series of 10 patients
}

\author{
Berna Yurttaş ${ }^{1}$ - Mert Oztas ${ }^{1}$ - Ali Tunc ${ }^{2}$. Illker İnanç Balkan ${ }^{3} \cdot$ Omer Fehmi Tabak ${ }^{3}$. Vedat Hamuryudan ${ }^{1}$. \\ Emire Seyahi ${ }^{1}$ (i)
}

Received: 31 May 2020 / Accepted: 27 June 2020 / Published online: 9 July 2020

(c) Società Italiana di Medicina Interna (SIMI) 2020

Coronavirus disease 2019 (COVID-19), caused by SARS$\mathrm{CoV}-2$, is the cause of the global pandemic that originated in China in December 2019 [1]. It had spread all over Turkey in March 2020, Istanbul being hit the hardest. As of 28 May 2020 , the total number of confirmed cases in the country is over 161,000 of which 124,400 have recovered and 4500 have died [2].

The most common symptoms of COVID-19 are fever and cough, which can progress to pneumonia and acute respiratory distress syndrome (ARDS) or multi-organ failure [3]. Additionally, it may predispose to thrombotic disease, both in the venous and arterial circulations [4-7].

Being older, smoking and having comorbid medical conditions are associated with severe outcome among patients

\author{
Emire Seyahi \\ eseyahi@yahoo.com \\ Berna Yurttaş \\ bernactf2006@gmail.com \\ Mert Oztas \\ dr.mertoztas@gmail.com \\ Ali Tunc \\ dralitunc@gmail.com \\ İlker İnanç Balkan \\ ilker.balkan@istanbul.edu.tr \\ Omer Fehmi Tabak \\ ftabak@istanbul.edu.tr \\ Vedat Hamuryudan \\ vhamuryudan@yahoo.com \\ 1 Division of Rheumatology, Department of Internal \\ Medicine, Cerrahpasa Medical School, Istanbul University- \\ Cerrahpasa, Istanbul, Turkey \\ 2 Department of Internal Medicine, Cerrahpasa Medical \\ School, Istanbul University-Cerrahpasa, Istanbul, Turkey \\ 3 Department of Infectious Diseases and Clinical \\ Microbiology, Cerrahpasa Medical School, Istanbul \\ University-Cerrahpasa, Istanbul, Turkey
}

with COVID-19 [3]. It is yet not known whether patients with rheumatic diseases (RD) receiving immunosuppressive therapy are more susceptible to SARS-CoV-2 or not. Recently two European centers reported that the prevalence of SARS-CoV-2 infection among patients with systemic autoimmune diseases was comparable to that observed in the general population $[8,9]$. Both studies were done during a short period of time and had been completed while the outbreak was still going on. While more information about COVID-19 in this patient population is needed, close monitoring of such patients is warranted.

Behçet's syndrome (BS) is a complex disorder of unknown etiology, characterized by recurrent skin mucosa lesions and uveitis [10]. The usual onset is in the third decade. There is relapsing remitting course while the severity abates as the years pass [10]. Vascular involvement affecting both venous and arterial system is almost always associated with intensive thrombosis of inflammatory nature and can occur in up to $40 \%$ of cases [11]. Lower extremity veins are frequently affected followed by iliac veins and vena cava. Central nervous system (CNS) and joints may also be involved. Immunosuppressive agents along with colchicine are the mainstay of treatment [12].

In this article, we present a case series of BS with COVID-19 and describe their presentation, disease course, management and outcomes. This study was approved by the Ministry of Health COVID-19-related scientific research consortium.

We identified $10 \mathrm{BS}$ patients $(5 \mathrm{M} / 5 \mathrm{~F}$ ) diagnosed with COVID-19, between April 1 and 21 May 2020. Five patients were retrieved from the Cerrahpasa Medical Faculty COVID-19 inpatient database $(n=767)$. The remaining contacted us to ask whether they should continue their medication after having been diagnosed elsewhere. Data regarding initial signs and symptoms, laboratory analyses and detailed medical treatment related to COVID-19 were retrieved via the "Ministry of Health Public Health Data 
Management System" database. Additionally, we assessed whether patients had any exacerbation of BS lesions during infection.

COVID-19 diagnosis and management were done according to the guidelines defined by the Ministry of Health [13]. Diagnosis was relied on either PCR positivity or typical lesions on the thorax CT [14]. First-line treatment included hydroxychloroquine $400 \mathrm{mg} /$ day (800 mg loading) + azithromycine $250 \mathrm{mg}$ for 5 days (500 mg loading) \pm oseltamivir $150 \mathrm{mg} /$ day. Favipiravir was added in selected cases upon clinical findings, and tocilizumab was given in case of hyperinflammation/cytokine release syndrome.

Demographic and clinical characteristics of the patients are shown in Table 1. Eight of ten had been previously registered at our outpatient clinic, while two were followed by other centers. Their median age was 39.5 [IQR 36.5-45.5] years, and median disease duration was 15 [IQR 11.25-15.0] years. In addition to skin mucosa lesions, four patients had eye involvement, one had both eye and neurological involvement and one had large vessel disease. Except one patient who was off treatment (patient no. 1), all nine were using one of the following drugs either alone or in combination: colchicine $(n=5)$, azathioprine $(n=3)$, anti-TNF agents $(n=3)$ or prednisolone $(n=2)$.

Table 2 shows presenting symptoms, laboratory tests, length of hospital stay and management related to COVID19. All patients had presented with one or more related symptoms except patient no.6 who had been brought to the emergency unit with asphyxia after having hanged himself. He was coincidentally diagnosed with severe COVID-19 pneumonia in the full-body CT scan.

In total, six of ten patients were diagnosed with pneumonia of which three were PCR positive. The remaining four had tested positive with mild-to-moderate symptoms. Apart from one (patient no. 1) who had severe respiratory failure, none of the patients with pneumonia had respiratory distress (finger probe $\mathrm{O}_{2}$ saturation: $\geq 91 \%$ ). Eight patients were hospitalized of whom two were admitted to the intensive care unit (ICU). The median length of hospital stay was 7 days [IQR 5.5-10]. All patients received first-line treatment for COVID-19 (Table 2). Patient no. 1 died due to severe respiratory failure and patient no. 2 developed de novo deep vein thrombosis (DVT) short after having contracted pneumonia. Additionally, three patients reported exacerbations of oral ulcers or arthralgia.

\section{Description of cases}

Case no. 1 was 38 -year-old female with a remote history of BS diagnosed 21 years ago. Additionally, she was using valproic acid since childhood due to grand mal epilepsy. She had been off treatment for 3 years being clinically quiescent. On April 16, 2020 she presented with nasal stiffness and coughing. Her physical examination and thorax CT were initially found normal. She was started first-line treatment and sent home for self-quarantine. Four days later, after her symptoms worsened (temperature: $40.9^{\circ} \mathrm{C}$, arterial $\mathrm{O}_{2}$ saturation: $73 \%$ ), she had been hospitalized, was started favipravir, however, her situation did not improve (arterial $\mathrm{O}_{2}$ saturation: $65 \%$ ). She died due to the severe respiratory failure on the 25th of April.

Case 2 was a 37-year-old male with a history of BS diagnosed 15 years ago. Due to parenchymal CNS involvement with a progressive relapsing course, he received several immunosuppressive agents including cyclophosphamide and

Table 1 Demographic and clinical characteristics

\begin{tabular}{|c|c|c|c|c|c|c|c|c|}
\hline \multirow[t]{2}{*}{ Pt no } & \multirow[t]{2}{*}{ Age, gen } & \multirow[t]{2}{*}{ Dis. dur } & \multirow[t]{2}{*}{ BS phenotypes } & \multirow[t]{2}{*}{ Comorbidities } & \multicolumn{2}{|c|}{ Medical treatments for BS } & \multirow[t]{2}{*}{ Survival status } & \multirow{2}{*}{$\begin{array}{l}\text { Complica- } \\
\text { tions/exacer- } \\
\text { bations }\end{array}$} \\
\hline & & & & & Before COVID-19 & $\begin{array}{l}\text { During } \\
\text { COVID- } \\
19\end{array}$ & & \\
\hline 1 & $38, \mathrm{~F}$ & 21 & Eye & Epilepsy & None & None & Dead & \\
\hline 2 & $36, \mathrm{M}$ & 15 & $\mathrm{CNS}+$ eye & Anti-TNF-induced psoriasis & ADA, AZA, pred & Pred & Alive & De novo DVT \\
\hline 3 & $46, \mathrm{~F}$ & 12 & Skin-mucosa & None & Col & Col & Alive & Arthralgia \\
\hline 4 & $44, \mathrm{~F}$ & 15 & Vascular & Endometrium CA & IFX, Col & None & Alive & \\
\hline 5 & $50, \mathrm{~F}$ & 16 & Eye & None & Col & Col & Alive & Oral ulcers \\
\hline 6 & $56, \mathrm{M}$ & 15 & Skin-mucosa & Psychiatric disease & Col & Col & Alive & \\
\hline 7 & $20, \mathrm{~F}$ & 1 & Skin-mucosa & None & Col & Col & Alive & Oral ulcers \\
\hline 8 & $41, \mathrm{M}$ & 15 & Skin-mucosa & None & AZA, pred & None & Alive & \\
\hline 9 & $38, \mathrm{M}$ & 11 & Eye & None & AZA & None & Alive & \\
\hline 10 & $33, \mathrm{M}$ & 2 & Eye & None & ADA & None & Alive & \\
\hline
\end{tabular}

Pt patient, no number, gen gender, Dis Dur. disease duration, $B S$ Behçet's syndrome, $I C U$ Intensive Care Unit, $M$ male, $F$ female, $A D A$ adalimumab, $A Z A$ azathioprine, pred prednisolone, $I F X$ infliximab, $C o l$ colchicine, N/A not available, $C A$ cancer, $D V T$ deep vein thrombosis 


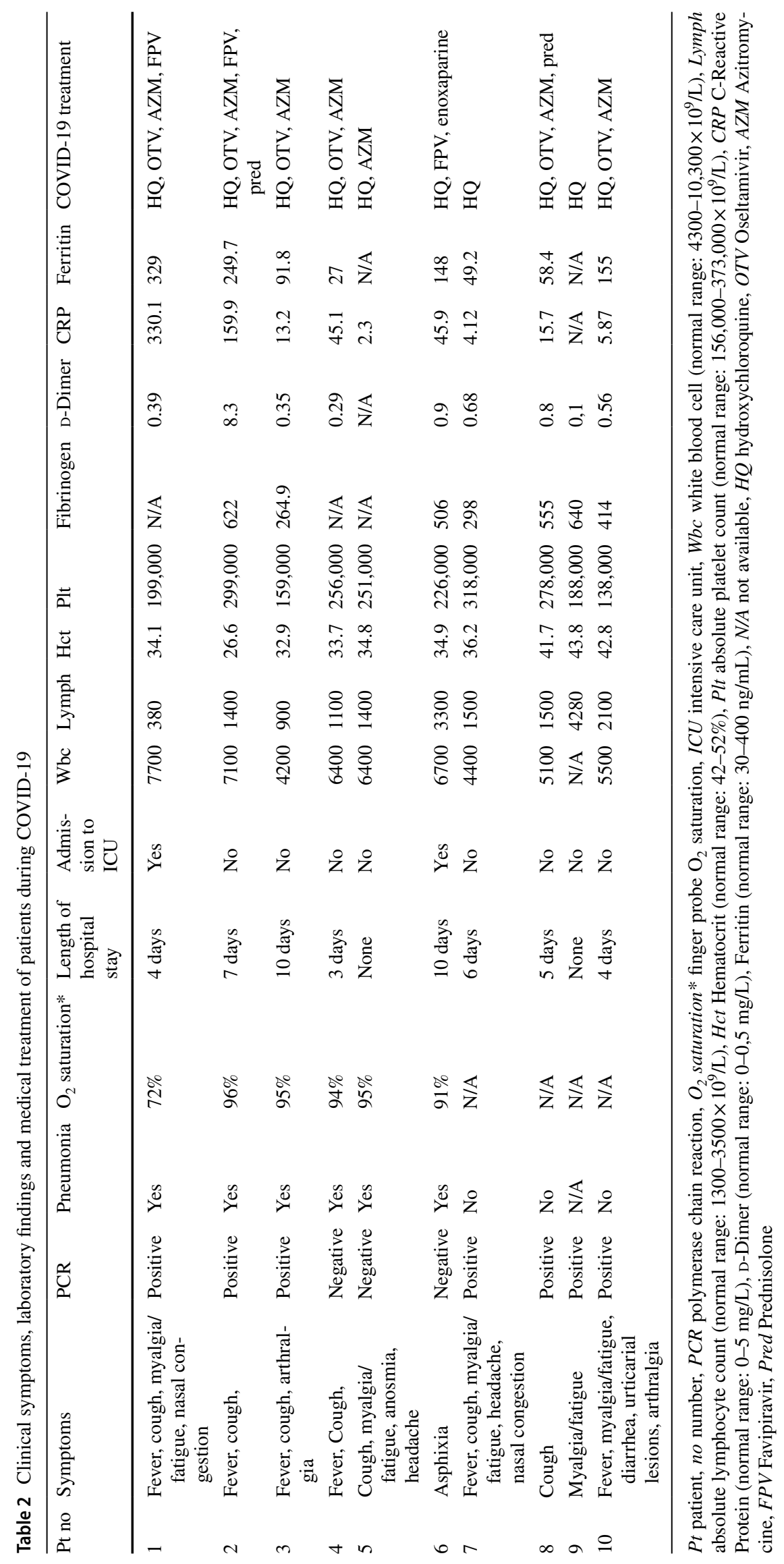


Table 3 Arterial and/or venous thrombosis in hospitalized COVID-19 patients
Klok et al. [4] Lodigiani et al. [5] Helms et al. [6] Middeldorp et al. [7]

\begin{tabular}{lllll}
\hline Intensive care unit & & & & \\
Number of total cases, $n$ & 184 & 48 & 150 & 75 \\
Pulmonary embolism, $n(\%)$ & $65(35.3)$ & $6(12.5)$ & $25(16.7)$ & $11(14.6)$ \\
Other VTE $^{\mathrm{a}}, n(\%)$ & $3(0.01)$ & $2(4.1)$ & $3(2)$ & $24(32)$ \\
Arterial $^{\mathrm{b}}, n(\%)$ & $7(0.03)$ & $4(8.2)$ & $4(2.7)$ & N/A \\
General ward & & & \\
Number of total cases, $n$ & N/A & 314 & N/A & 123 \\
$\begin{array}{l}\text { Pulmonary embolism, } n(\%) \\
\text { Other VTE }\end{array}, n(\%)$ & & $20(6.4)$ & & $2(1.6)$ \\
Arterial & \\
& & $4(1.2)$ & & $2(1.6)$ \\
\hline
\end{tabular}

N/A not available

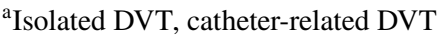

${ }^{\mathrm{b}}$ Acute coronary syndrome, stroke, limb ischemia, mesenteric ischemia infliximab. Recently, he was using adalimumab in addition to colchicine, azathioprine and prednisolone. He had been hospitalized on March 20, 2020, because of acute abundant gastrointestinal hemorrhage whose etiology was not clarified despite various investigations. The bleeding continued for about 6 days requiring several blood transfusions and then resolved spontaneously. He was found to have contracted COVID-19 on the first of April after a screening test done because of high CRP levels, while still being hospitalized. He did not have any symptom, and his physical examination was normal except sequel neurological findings. His PCR test was positive and thorax CT disclosed several ground glass opacities. He received first-line treatment for COVID19 for 1 week while being on prednisolone $20 \mathrm{mg} /$ day. Eight days after COVID-19 diagnosis, Favipiravir 2 mg/day was started and continued for 5 days due to high CRP levels and progression of the lesions on the thorax CT. On the 9th day, he complained of acute swelling and pain on the right leg. Doppler USG showed acute deep vein thrombosis starting from popliteal vein extending to external iliac vein. Lupus anticoagulant and anti-phospholipid antibodies were negative and no abnormality was detected in the thrombophilia panel. Prednisolone dose was increased to $40 \mathrm{mg} / \mathrm{day}$, and interferon $5 \mathrm{MU}$ daily was started. Anticoagulants were not initiated because of the recent history of gastrointestinal bleeding. On the 14th day, his right leg pain and swelling resolved and his CRP levels became normal. PCR test for COVID-19 became twice negative. A control Doppler examination done 4 weeks later disclosed partial recanalization of thrombus.

Case no 3, 4, 5 and 6 had been diagnosed with COVID-19 pneumonia. Only one tested positive. Three were hospitalized of whom 1 required ICU admission. Three patients had exacerbation of oral ulcers or arthralgia.

Case 7, 8, 9 and 10 tested positive for COVID-19 because of fever and myalgia. Their thorax CT scans or chest X-ray were found to be normal. No complication associated with COVID -19 or BS was observed.

Our case series suggests that BS patients are much younger and appear to have increased risk for severe outcome when infected with COVID-19 compared to the general population. Pneumonia which progressed to ARDS leading to death in one patient was rather frequent occurring in six of ten. Moreover, one patient developed DVT and three patients experienced flares of oral ulcers or arthralgia. In line with our observations, very recently a study from Wuhan, China, reported that respiratory failure was more commonly observed in RD patients infected with COVID19 compared to those without RD [15]. The same study also observed exacerbations of RD during COVID-19 infection [15]. Similarly, several studies reported high incidence of a severe form of Kawasaki disease in association with the SARS-CoV-2 epidemic [16].

Venous thrombosis in BS usually occurs either at disease onset or in the early years and run a relapsing course ultimately causing stenosis or occlusion over the years. It is also unusual to see association of DVT with parenchymal CNS involvement. De novo DVT after 15 years of disease onset in patient no. 2 could be most probably induced by COVID-19. Several studies disclosed an increased arterial and venous thrombotic complications in especially severely ill patients with COVID-19 as summarized in Table 3 [4-7]. It seems that the risk appears to be higher than that observed among non-COVID-19 cases and those with Influenza pneumonia [4-7]. Thromboembolic events may occur in hospitalized patients receiving thrombo-prophylaxis either in general ward conditions or in ICU [4-7]. It is assumed to be caused by endothelitis and hypercoagulable state as a consequence of SARS-CoV-2 related endothelial injury and dysregulated inflammatory response [17].

The effect of immunosuppression on the prevention or on the course of COVID-19 is unknown. Despite in vitro 
evidence suggesting that immunosuppressives may inhibit viral replication, long-term use of these agents however seems to increase susceptibility to infection $[3,15,18]$. The effect of colchicine on COVID-19 infection should be also clarified. Colchicine has been known to decrease neutrophil migration and inhibit formation of inflammasome which has a major role in ARDS pathogenesis [19]. Our case series sample is not large enough to answer these questions; nevertheless, none of the drugs seem to prevent COVID-19 since nine of ten patients were using either an immunosuppressive drug or colchicine.

Of note, we did not routinely test BS patients who were asymptomatic or we did not investigate whole BS population for whether they were contracted COVID-19 or hospitalized. Those patients with milder infection or those who could not reach us due to quarantine and other restrictions may not be represented as well.

The high frequency of pneumonia and occurrence of thrombosis in this case series calls for close monitoring of BS patients as well as other immune compromised patients during SARS-Cov-2 pandemic.

Funding We did not receive any financial support.

\section{Compliance with ethical standards}

Conflict of interest We declare no competing interests.

Statements on human and animal rights All procedures performed in the study (involving human participants) were in accordance with the ethical standards of the institutional research committee and with the 1964 Helsinki declaration and its later amendments or comparable ethical standards.

Informed consent Informed consent was collected from all alive human participants involved in the study. The mother of the deceased patient gave oral informed consent.

\section{References}

1. WHO (2020) Novel coronavirus-China. https://www.who.int/ csr/don/12-january-2020-novel-coronavirus-china/en/. Accessed 19 Jan 2020

2. https://covid19.saglik.gov.tr. Accessed 23 May 2020

3. Gandhi RT, Lynch JB, Del Rio C (2020) Mild or moderate Covid19. N Engl J Med. https://doi.org/10.1056/NEJMcp2009249

4. Klok FA, Kruip MJHA, van der Meer NJM et al (2020) Confirmation of the high cumulative incidence of thrombotic complications in critically ill ICU patients with COVID-19: an updated analysis. Thromb Res. https://doi.org/10.1016/j.thromres.2020.04.041 (published online ahead of print, 2020 Apr 30)

5. Lodigiani C, Iapichino G, Carenzo L et al (2020) Venous and arterial thromboembolic complications in COVID-19 patients admitted to an academic hospital in Milan, Italy. Thromb Res 191:9-14 (published online ahead of print, 2020 Apr 23)
6. Helms J, Tacquard C, Severac F et al (2020) High risk of thrombosis in patients with severe SARS-CoV-2 infection: a multicenter prospective cohort study. Intensive Care Med. https://doi. org/10.1007/s00134-020-06062-x (published online ahead of print, 2020 May 4)

7. Middeldorp S, Coppens M, van Haaps TF et al (2020) Incidence of venous thromboembolism in hospitalized patients with COVID-19. J Thromb Haemost. https://doi.org/10.1111/jth.14888 (published online ahead of print, 2020 May 5)

8. Michelena X, Borrell H, López-Corbeto M et al (2020) Incidence of COVID-19 in a cohort of adult and paediatric patients with rheumatic diseases treated with targeted biologic and synthetic disease-modifying anti-rheumatic drugs. Semin Arthritis Rheum 50(4):564-570. https://doi.org/10.1016/j.semarthrit.2020.05.001 (published online ahead of print, 2020 May 16)

9. Emmi G, Bettiol A, Mattioli I et al (2020) SARS-CoV-2 infection among patients with systemic autoimmune diseases. Autoimmun Rev 19(7):102575. https://doi.org/10.1016/j.autrev.2020.102575

10. Yazici H, Seyahi E, Hatemi G, Yazici Y (2018) Behçet syndrome: a contemporary view. Nat Rev Rheumatol 14(2):107-119. https ://doi.org/10.1038/nrrheum.2017.208 (published correction appears in Nat Rev Rheumatol. 2018 Jan 24;14 (2):119)

11. Seyahi E (2019) Phenotypes in Behçet's syndrome. Intern Emerg Med 14(5):677-689. https://doi.org/10.1007/s11739-019-02046-y

12. Esatoglu SN, Hatemi G (2019) Update on the treatment of Behçet's syndrome. Intern Emerg Med 14(5):661-675. https:// doi.org/10.1007/s11739-019-02035

13. https://hsgm.saglik.gov.tr/depo/birimler/goc_sagligi/covid19/ rehber/COVID-19_Rehberi20200414_eng_v4_002_14.05.2020. pdf

14. Fang Y, Zhang H, Xie J et al (2020) Sensitivity of chest CT for COVID-19: comparison to RT-PCR. Radiology. https://doi. org/10.1148/radiol.2020200432 (published online ahead of print, 2020 Feb 19)

15. Ye C, Cai S, Shen G et al (2020) Clinical features of rheumatic patients infected with COVID-19 in Wuhan, China. Ann Rheum Dis. https://doi.org/10.1136/annrheumdis-2020-217627 (published online ahead of print, 2020 May 22)

16. Verdoni L, Mazza A, Gervasoni A et al (2020) An outbreak of severe Kawasaki-like disease at the Italian epicentre of the SARSCoV-2 epidemic: an observational cohort study. Lancet. https:// doi.org/10.1016/S0140-6736(20)31103-X (published online ahead of print, 2020 May 13)

17. Ackermann M, Verleden SE, Kuehnel M et al (2020) Pulmonary vascular endothelialitis, thrombosis, and angiogenesis in Covid19. N Engl J Med. https://doi.org/10.1056/NEJMoa2015432 (published online ahead of print, 2020 May 21)

18. Latif F, Farr MA, Clerkin KJ et al (2020) Characteristics and outcomes of recipients of heart transplant with coronavirus disease 2019. JAMA Cardiol. https://doi.org/10.1001/jamacardio .2020 .2159 (Epub ahead of print)

19. Deftereos S, Giannopoulos G, Vrachatis DA et al (2020) Colchicine as a potent anti-inflammatory treatment in COVID-19: can we teach an old dog new tricks? Eur Heart J Cardiovasc Pharmacother. https://doi.org/10.1093/ehjcvp/pvaa033 (published online ahead of print, 2020 Apr 27)

Publisher's Note Springer Nature remains neutral with regard to jurisdictional claims in published maps and institutional affiliations. 